\title{
Combined associations of hs-CRP and cognitive function with all-cause mortality among oldest-old adults in Chinese longevity areas: a prospective cohort study
}

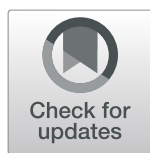

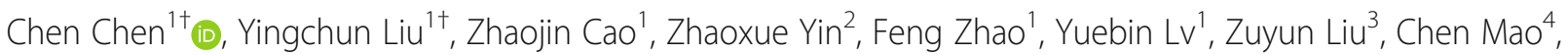
Shixun Song ${ }^{1}$, Ling Liu', Yingli Qu', Saisai Ji', Jun Duan ${ }^{1}$, Jiaonan Wang ${ }^{1,5}$, Virginia Byers Kraus ${ }^{6}$, Yi Zeng ${ }^{7,8}$ and Xiaoming Shi ${ }^{1,5^{*}}$

\begin{abstract}
Background: Inflammatory markers, such as high sensitivity C-reactive protein (hs-CRP), and cognitive impairment (CI) are associated with mortality; CRP is related to the deterioration of $\mathrm{Cl}$. However, it is still unknown whether these two indices predict mortality independent of each other. Furthermore, their joint effect on all-cause mortality has not been well established, especially in oldest-old adults.

Methods: Based on data from the 2012 wave of the Chinese Longitudinal Healthy Longevity Survey (CLHLS), we included 1447 oldest-old adults (mean age 84.7 years and 58.7\% were female, weighted) with information on hsCRP (stratified by a cutoff value of $3.0 \mathrm{mg} / \mathrm{L}$ ) and cognition (quantified by Mini-Mental Status Examination (MMSE) scored according to the personal educational level) at baseline. Mortality was assessed in followed 2014 and 2017 waves. Cox proportional hazards regression models were used, with adjustment for hs-CRP and cognition (mutually controlled) and several traditional mortality risk factors.
\end{abstract}

Results: During a median follow-up period of 32.8 months (Q1-Q3, 9.7-59.0 months), 826 participants died. Hs-CRP $[H R>3.0 \mathrm{mg} / \mathrm{L}$ vs $\leq 3.0 \mathrm{mg} / \mathrm{L}: 1.64(95 \% \mathrm{Cl}, 1.17,2.30)]$ and cognition $[\mathrm{HR}$ Cl vs normal: 2.30 (95\% Cl, 1.64, 3.21)] each was independent predictor of all-cause mortality, even after accounting for each other and other covariates. Monotonic and positive associations were observed in combined analyses, in which the highest mortality risk was obtained in elders with both high hs-CRP $>3.0 \mathrm{mg} / \mathrm{L}$ and $\mathrm{Cl}[\mathrm{HR}: 3.56(95 \% \mathrm{Cl}, 2.35,5.38)]$. The combined effects were stronger in male and younger oldest-old (aged 80-89 years).

Conclusion: High hs-CRP and Cl, both individually and jointly, were associated with increased all-cause mortality risks in Chinese oldest-old. Intervention strategies for preventing inflammation and maintaining adequate cognitive function may be more important in male and younger oldest-old for reducing mortality risk.

Keywords: Hs-CRP, Cognition, Mortality, Oldest-old

\footnotetext{
* Correspondence: shixm@chinacdc.cn

${ }^{\dagger}$ Chen Chen and Yingchun Liu contributed equally to this work.

${ }^{1}$ National Institute of Environmental and Health, Chinese Center for Disease

Control and Prevention, Bejing 100021, People's Republic of China

${ }^{5}$ Center for Global Health, School of Public Health, Nanjing Medical

University, Nanjing 211166, Jiangsu, China

Full list of author information is available at the end of the article
}

(c) The Author(s). 2019 Open Access This article is distributed under the terms of the Creative Commons Attribution 4.0 International License (http://creativecommons.org/licenses/by/4.0/), which permits unrestricted use, distribution, and reproduction in any medium, provided you give appropriate credit to the original author(s) and the source, provide a link to the Creative Commons license, and indicate if changes were made. The Creative Commons Public Domain Dedication waiver (http://creativecommons.org/publicdomain/zero/1.0/) applies to the data made available in this article, unless otherwise stated. 


\section{Background}

C-reactive protein (CRP) is an acute-phase reactant that is a strong marker for underlying systemic inflammation. Based on laboratory and epidemiologic data, inflammation promotes both the initiation and the progression of atherosclerosis [1,2]. Elevated levels of CRP are associated with increased risk of cardiovascular events [3-5] and mortality $[6,7]$. This association is mostly apparent with CRP levels of $>3.0 \mathrm{mg} / \mathrm{L}$ [8], which has become a well-established classification criterion for predicting high risk level of cardiovascular disease (CVD) $[9,10]$. However, the high risk threshold value varies across different age groups. Though higher levels of CRP represent a risk factor for all-cause mortality in both middleaged [11, 12], 65 -[13] and 75-year-old [14] cohorts, this association is attenuated in 80- and 85-year-old cohorts [15]. Furthermore, data about the epidemiology and predictive value of CRP, especially in oldest-old (aged $\geq 80$ years), are sparse $[15,16]$; the two previous studies of this age group were limited to less than 300 older persons each. Therefore, the predictive value of elevated CRP on mortality risk needs further evaluation in oldestold adults aged 80 years or older.

Cognitive decline is often associated with ageing, and even mild levels of cognitive impairment (CI) has been associated with increased risk of mortality in the elderly [17]. Inflammatory markers, such as CRP, have been found in the $\beta$-amyloid plaques and neurofibrillary tangles in patients with dementia or CI $[18,19]$. It is still unclear whether participants with high CRP level are also those with poor cognitive function $[20,21]$. Moreover, to our knowledge, little is known about the combined effects of CRP level and cognitive function on allcause mortality risk, especially in the oldest-old adults. It is also unknown whether these two indices predict mortality independent of each other.

In this study, we hypothesized that high sensitivity CRP (hs-CRP) level and cognitive function, both individually and jointly, are associated with the length of remaining life in Chinese elderly. To evaluate this hypothesis we investigated the relationship between hsCRP and cognitive performance with all-cause mortality in the oldest-old using a large population-based cohort of participants aged 80 years or older who were followed up for 5 years.

\section{Methods}

\section{Study population}

Participants for this study were ascertained from the 8 longevity areas during the sixth wave of the Chinese Longitudinal Healthy Longevity Survey (CLHLS) in 2012. The 8 areas represented $1 / 3$ of the longevity areas selected by the Chinese Society of Gerontology in 2011 [22]. Compared with other areas, longevity areas have higher densities of oldest old adults, especially for centenarians $(>7 / 100,000)$, and higher life expectancies. A total of 1535 participants aged 80 years or older were enrolled in the baseline survey, including 555 octogenarians, 461 nonagenarians and 519 centenarians. Details of the study design and its sampling method have been described previously [23]. After exclusion of 29 subjects due to missing data on hs-CRP value and 59 subjects on cognition, a total of 1447 oldest-old adults were included in the final analysis. The followed two waves of the survey were carried out in 2014 and 2017. The study was approved by the Ethics Committee of Peking University and Duke University. All participants signed written informed consent.

\section{High sensitivity CRP}

Overnight fasting blood samples were collected from all participants. Plasma levels of hs-CRP were measured by immunoturbidimetric assay (Roche Diagnostic, Mannheim, Germany) using an Automatic Biochemistry Analyzer (Hitachi 7180, Japan). All laboratory analyses were conducted by the central clinical lab at Capital Medical University in Beijing. The minimal detectable concentration of hs-CRP was $0.11 \mathrm{mg} / \mathrm{L}$. Quality control measures in the laboratory were described previously [24]. We used both hs-CRP quartiles and a binary variable (the cutoff value was $3.0 \mathrm{mg} / \mathrm{L}$ ) for the individual association analyses and applied the binary variable in the combined association analyses.

\section{Cognition}

The Mini-Mental Status Examination (MMSE), which has been a widely used 30-point assessment tool for screening cognitive impairment, was administrated to all participants. The designation of cognitive impairment was based on the MMSE score taking into account the educational level $[25,26]$ : participants with an MMSE score less than 18 and no formal schooling, or those with an MMSE score less than 24 and with at least 1 year of formal schooling were defined as having cognitive impairment; otherwise, those who failed to meet these criteria were defined as having normal cognition.

\section{Date of death}

The date of death was collected from official death certificates when available; otherwise, the next-of-kin and local village doctor were consulted. Survival time (in months) was calculated from the interview date at baseline until the date of death (for participants who died), the interview date of follow-up survey (for participants who were alive), or administrative censoring date (i.e., the middle date between the last survey when the participant was interviewed and the subsequent survey, for 
participants who were lost to follow-up), whichever came first.

\section{Covariates}

Sociodemographic characteristics included age, sex (male vs female), education (any formal education, defined as at least 1 year of formal schooling), and current marital status (currently married vs other). Data collected on health behaviors and characteristics included current smoking, current alcohol consuming, regular exercise (yes vs no), and being able to get adequate medical service for any illness (yes vs no). Self-reported history of chronic diseases included hypertension, diabetes mellitus, heart disease, stroke and cerebrovascular disease, respiratory disease and cancer. Physical examination data included weight and height (for body mass index (BMI) calculated as weight in kilograms divided by height in meters squared), and waist circumference (WC) collected using standardized measurement protocols [27]. Central obesity (yes vs no) was defined as $W C \geq 85 \mathrm{~cm}$ in men and $W C \geq 80 \mathrm{~cm}$ in women. These covariates have been well defined and studied in CLHLS, showing important effects both on hs-CRP level [24] and mortality [28].

\section{Statistical analyses}

In all analyses, we adopted a survey weight variable that was constructed according to the distribution of age, sex, and urban/rural residence in the Chinese population in the survey year [23]. To observe the combined effects of the inflammation marker and cognition on mortality, we categorized hs-CRP and cognition into binary variables and created a 4-level joint hs-CRP/cognition variable that included the following groups:

Group 1: hs-CRP $\leq 3.0 \mathrm{mg} / \mathrm{L}$ and normal cognition Group 2: hs-CRP $>3.0 \mathrm{mg} / \mathrm{L}$ and normal cognition Group 3: hs-CRP $\leq 3.0 \mathrm{mg} / \mathrm{L}$ and cognitive impairment Group 4: hs-CRP > $3.0 \mathrm{mg} / \mathrm{L}$ and cognitive impairment

Characteristics of the study population were presented as means ( \pm standard deviation $[S D]$ ) or percentages in the full sample and by the 4 combined groups. KaplanMeier analysis was used to compare survival curves, and log-rank test was used to assess significance. The individual associations of hs-CRP levels with mortality without and with adjustment for cognitive impairment was analyzed (and vice versa). The combined associations of hs-CRP/cognition groups with risk of mortality were then performed according to the above 4 groups. We added an interaction term, inflammation marker*cognition, in models with hs-CRP and cognitive impairment included as independent to examine whether the association of hs-CRP levels with risk of death was modified by cognition groups (and vice versa).

Two weighted Cox proportional hazards models were used with the outcome of all-cause mortality. Model 1 was adjusted for age and sex; model 2 additionally adjusted for education, drinking, smoking, marital status, regular exercise, medication, BMI, central obesity, selfreported history of hypertension, diabetes mellitus, heart disease, stroke and cerebrovascular disease, respiratory disease and cancer; Education was not included in model 2 when cognition and the combined hs-CRP/cognition variable were analyzed because we defined cognition status according to personal education levels. We documented the Hazard ratios (HRs) and 95\% confidence intervals (CIs). We also assessed the ability of specific variables to predict mortality by estimating the Harrell's C-statistics [29].

Next, we repeated the above analysis for two subgroups: age (80-89 years vs. $\geq 90$ years) and sex (female vs. male). The interactions between age, sex and the 4level joint variable for mortality risk were evaluated in model 2 to determine whether the joint effect was the same in each subgroup.

To test the robustness of our results, we performed several sensitivity analyses. First, we repeated models with replacement of missing data on sociodemographic factors using mean imputation techniques. Second, we repeated models by excluding the participants with extreme high hs-CRP levels (>10 mg/L), generally considered an indication of infection [30]. Third, we excluded individuals who died in the first two years to avoid the confounding of mortality due to preexisting disease. Fourth, we reran the combined models without adjustment for several chronic diseases in order to avoid unfavorable over-adjusted estimates. All statistical analyses were performed using SAS version 9.4 (SAS Institute, Cary, NC). $P<0.05$ (two-tailed) was considered statistically significant.

\section{Results}

\section{Basic characteristics of study participants}

During an unweighted median follow-up period of 32.8 months (Q1-Q3, 9.7-59.0 months); a total of 826 participants died, 287 were lost to follow-up, and 334 survived. The median level of hs-CRP was $1.07 \mathrm{mg} / \mathrm{L} ; 9.1 \%(n=$ 137) of the participants had hs-CRP levels higher than $10 \mathrm{mg} / \mathrm{L}$. The median MMSE score was 23.0; the prevalence of CI was $37.2 \%$ (28.2\% for males and $42.1 \%$ for females). We did not find significant differences in the baseline characteristics between individuals who were lost to follow-up and those who were remained in the study, except that a higher proportion of regular exercise was found in the former group (Additional file 1: Table S2). Table 1 lists the characteristics of all study participants 
Table 1 Baseline characteristics of study participants across the 4 groups ( $N=1447)$

\begin{tabular}{|c|c|c|c|c|c|c|}
\hline Characteristic & $\begin{array}{l}\text { Overall }^{a} \\
(n=1447)\end{array}$ & $\begin{array}{l}\text { hs-CRP } \leq 3.0 \mathrm{mg} / \mathrm{L} \& \text { normal } \\
\text { cognition }(n=689)\end{array}$ & $\begin{array}{l}\text { hs-CRP }>3.0 \mathrm{mg} / \mathrm{L} \& \text { normal } \\
\text { cognition }(n=220)\end{array}$ & $\begin{array}{l}\mathrm{hs}-\mathrm{CRP} \leq 3.0 \mathrm{mg} / \mathrm{L} \mathrm{\&} \\
\mathrm{Cl}(n=389)\end{array}$ & $\begin{array}{l}\text { hs-CRP }>3.0 \mathrm{mg} / \mathrm{L} \& \\
\mathrm{Cl}(n=149)\end{array}$ & $\begin{array}{l}\mathrm{P} \text { for } \\
\text { trend }\end{array}$ \\
\hline Age, years, mean (SD) & $84.7(0.2)$ & $84.3(0.2)$ & $83.9(0.3)$ & $86.9(0.7)$ & $86.5(0.8)$ & $\begin{array}{l}< \\
0.001\end{array}$ \\
\hline Female & $899(58.7)$ & $417(58.2)$ & $115(52.5)$ & $277(72.2)$ & $90(54.7)$ & 0.369 \\
\hline$\geq 1$ Years of education & $326(30.8)$ & $175(31.4)$ & $54(35.2)$ & $71(22.1)$ & $26(29.6)$ & 0.385 \\
\hline $\begin{array}{l}\text { Currently married, } \\
\text { yes }^{\text {b }}\end{array}$ & $297(37.9)$ & $195(41.5)$ & $55(44.5)$ & $31(15.5)$ & $16(23.3)$ & $\begin{array}{l}< \\
0.001\end{array}$ \\
\hline Regular exercise, yes ${ }^{b}$ & $182(16.1)$ & $119(19.3)$ & $27(14.5)$ & $28(8.4)$ & $8(1.6)$ & $\begin{array}{l}< \\
0.001\end{array}$ \\
\hline Current smoking, yes ${ }^{b}$ & $151(11.8)$ & $83(14.0)$ & $28(9.1)$ & $28(6.9)$ & $12(6.6)$ & 0.014 \\
\hline $\begin{array}{l}\text { Current alcohol } \\
\text { drinking, yes }^{b}\end{array}$ & 169 (13.0) & $97(15.5)$ & $23(9.5)$ & $35(8.3)$ & $14(6.4)$ & 0.014 \\
\hline $\begin{array}{l}\text { Body mass index, } \mathrm{kg} / \\
\mathrm{m}^{2} \text {, mean (SD) }\end{array}$ & $21.4(0.3)$ & $21.3(0.3)$ & $20.7(0.5)$ & $23.2(2.0)$ & $21.4(0.8)$ & 0.424 \\
\hline Central obesity, yes ${ }^{\mathrm{bc}}$ & $465(39.8)$ & $243(40.0)$ & $74(41.6)$ & $120(38.4)$ & $28(34.6)$ & 0.716 \\
\hline $\begin{array}{l}\text { Adequate medical } \\
\text { service, yes }{ }^{b}\end{array}$ & $\begin{array}{l}1311 \\
(94.2)\end{array}$ & $643(94.0)$ & $201(96.0)$ & $342(91.9)$ & $125(94.7)$ & 0.855 \\
\hline
\end{tabular}

Values are given as No. (\%) unless otherwise stated. No. was based on study samples (unweighted). Means (SD) and percentages were weighted population estimates. $\mathrm{Cl}$, cognitive impairment

${ }^{a}$ Of 1447 participants, 46 with missing data on the weight variable were excluded for calculating weighted population estimates

${ }^{b}$ Numbers of missing data ranged from 3 to 41 (8 for married status, 41 for regular exercise, 8 for current smoking, 3 for alcohol drinking, 18 for central obesity, and 6 for adequate medication)

${ }^{c}$ Central obesity (yes vs no) was defined as waist circumference (WC) $\geq 85 \mathrm{~cm}$ in men and WC $\geq 80 \mathrm{~cm}$ in women

across the 4 mutually exclusive hs-CRP/cognition groups. The mean (SD) age of the 1447 participants at baseline was 85 (0.2) years (weighted, hereafter); and $59 \%(n=899)$ were female. Participants with both higher hs-CRP $(>3.0 \mathrm{mg} / \mathrm{L})$ and worse cognition were older, were less likely to take regular exercise, smoke, drink, and currently married ( $\mathrm{P}$ for trend all $<0.05$, Table 1 ), and more likely to suffer with diabetes, stroke and cerebrovascular disease ( $\mathrm{P}$ for trend all< 0.05 , Additional file 1: Table S1). Kaplan-Meier survival curves for these 4 groups separated early and the separation persisted throughout the subsequent 5 years (log-rank test for trend $<0.01$, Fig. 1). The median survival time from group 1 to 4 were 55.7, 48.0, 25.6 and 17.4 months, respectively.

\section{Individual associations of hs-CRP and cognitive status with all-cause mortality}

Table 2 shows the associations of hs-CRP levels with allcause mortality. After adjustment for age and sex (Model 1), there was a graded association between higher hs-CRP levels and increased mortality that was slightly decreased after consideration of cognition ( $P$ for trend all $<0.05$ ). Compared with participants in the lowest hs-CRP quartile group, those in the highest quartile group had a nearly 2fold increased risk for death [HR Q4 vs Q1: 2.02 (95\% CI, $1.25,3.26)]$. After additional adjustment for smoking, marital status, regular exercise, central obesity, selfreported history of hypertension, respiratory diseases, and cancer (Model 2), and after accounting for differences in cognitive status, the association between hs-CRP levels with mortality was slightly more pronounced [HR Q4 vs Q1: 2.10 (95\% CI, 1.30, 3.39)] (P-trend< 0.05). Similar statistically significant results were obtained when hs-CRP was categorized by the cutoff value of $3.0 \mathrm{mg} / \mathrm{L}$ (Table 2) and when assessed as a continuous variable (Additional file 1: Table S2).

Similarly, after adjustment for multiple mortality risk factors and consideration of differences in baseline hsCRP levels, poorer cognitive function $(\mathrm{CI})$ was associated with higher risk of mortality [HR CI vs normal: 2.30 (95\% CI, 1.64, 3.21)] (Table 2).

\section{Combined associations of hs-CRP and cognitive status on all-cause mortality}

Monotonic and positive associations were observed in combined analyses, the higher the joint hs-CRP/cognition group from group1 to group 4, the higher the risk of death (P-trend all<0.01, Table 3; Fig. 2a). In addition, the joint analysis suggested the presence of an interaction between hs-CRP and cognitive status for prediction of 5-year mortality ( $P$ for interaction $<0.01$, Table 3). For instance, among participants with normal cognition, high hs-CRP group (>3.0 mg/L) was associated with a 1.7-fold [HR Group2 vs. Group1: 1.70 vs. 1.00] increase in the risk for mortality compared to those in the low hs-CRP group $(\leq 3.0 \mathrm{mg} / \mathrm{L})$. However, among participants with $\mathrm{CI}$, the risk estimate was increased only by $49 \%$ among elders with high hs-CRP (> 


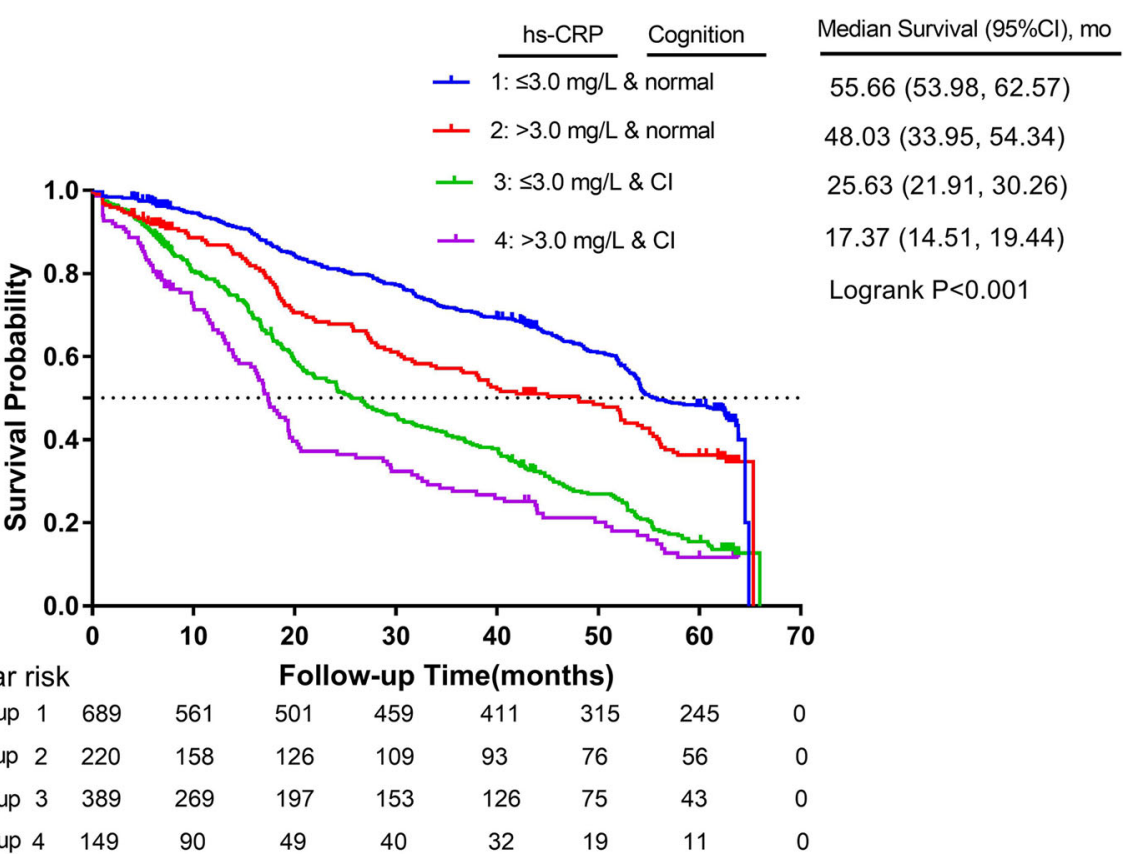

Fig. 1 Kaplan-Meier survival curves for Chinese oldest-old stratified by the 4-level joint hs-CRP/cognition groups ( $N=1447$ ). Group 1 (hs-CRP $\leq 3.0 \mathrm{mg} /$ $\mathrm{L}$ and normal cognition), group 2 (hs-CRP $>3.0 \mathrm{mg} / \mathrm{L}$ and normal cognition), group 3 (hs-CRP $\leq 3.0 \mathrm{mg} / \mathrm{L}$ and $\mathrm{Cl}$ ), group 4 (hs-CRP $>3.0 \mathrm{mg} / \mathrm{L}$ and $\mathrm{Cl}$ )

$3.0 \mathrm{mg} / \mathrm{L}$ ) [HR Group4 vs. Group3: 3.56 vs. 2.39]. The Harrell's C-statistic, for the hs-CRP/cognition combined variable was 0.63 (95\%CI, $0.60-0.66)$, followed by cognitive status $0.61(95 \% \mathrm{CI}, 0.58-0.64)$ and hs-CRP 0.54 (95\%CI, 0.51-0.58, for quartiles).

\section{Subgroup and sensitivity analyses}

Stratified results generally did not change appreciably in different age and sex subgroups (Fig. $2 b$ and c) except for some of the non-significant effect estimates in the male subgroup. Interestingly, we observed that the estimated mortality risk was stronger in males and octogenarians compared with females, nonagenarians and centenarians (all P for interaction $<0.01$ ).

In sensitivity analyses, we found that: (1) the results were materially unchanged after missing data were imputed; (2) exclusion of individuals who had abnormal hs-CRP values at baseline $(n=137)$ did not affect the associations of hs-CRP, cognitive status and mortality [HR Group4 vs. Group1: 3.74 (2.25-6.23), Fig. 2a]; (3)

Table 2 Hazard ratios for the individual associations of hs-CRP levels and cognitive status with all-cause mortality $(N=1447)$

\begin{tabular}{|c|c|c|c|c|}
\hline$\overline{\mathrm{hs}-\mathrm{CRP}(\mathrm{mg} / \mathrm{L})}$ & Model 1 & Model $1+$ cognition & Model 2 & Model $2+$ cognition $^{a}$ \\
\hline \multicolumn{5}{|l|}{ Cut-off at $3.0 \mathrm{mg} / \mathrm{L}$} \\
\hline Low hs-CRP ( $\leq 3.0$ mg/L) & 1 & 1 & 1 & 1 \\
\hline High hs-CRP (> 3.0 mg/L) & $1.75(1.30,2.37)$ & $1.67(1.19,2.34)$ & $1.76(1.30,2.37)$ & $1.64(1.17,2.30)$ \\
\hline \multicolumn{5}{|l|}{ Cut-offs by quartiles } \\
\hline $\mathrm{Q} 1(<0.41)$ & 1 & 1 & 1 & 1 \\
\hline Q2(0.41-1.05) & $1.32(0.87,2.01)$ & $1.36(0.87,2.12)$ & $1.49(0.95,2.35)$ & $1.47(0.94,2.30)$ \\
\hline Q3(1.06-3.05) & $1.24(0.82,1.89)$ & $1.14(0.71,1.83)$ & $1.40(0.89,2.19)$ & $1.19(0.73,1.92)$ \\
\hline $\mathrm{Q} 4(\geq 3.06)$ & $2.20(1.45,3.32)$ & $2.02(1.25,3.26)$ & $2.39(1.53,3.73)$ & $2.10(1.30,3.39)$ \\
\hline$P$ for trend & $<0.001$ & 0.009 & $<0.001$ & 0.008 \\
\hline Cognition groups & Model 1 & Model $1+$ hs-CRP & Model $2^{a}$ & Model $2+$ hs-CRP ${ }^{a}$ \\
\hline Normal cognition & 1 & 1 & 1 & 1 \\
\hline Cognitive impairment & $2.72(1.90,3.91)$ & $2.29(1.63,3.21)$ & $2.73(1.91,3.91)$ & $2.30(1.64,3.21)$ \\
\hline
\end{tabular}

Model 1 adjusted for age and sex; model 2 further adjusted for education, drinking, smoking, marital status, regular exercise, medication, BMI, central obesity, selfreported history of hypertension, diabetes mellitus, heart disease, stroke and cerebrovascular disease, respiratory disease and cancer

${ }^{a}$ Education was not included 
Table 3 Hazard ratios for the combined associations of hs-CRP and cognitive impairment with all-cause mortality $(N=1447)$

\begin{tabular}{llll}
\hline Groups/HR & No. of deaths & Model 1 & ${\text { Model } 2^{\text {a }}}$ \\
\hline 1: hs-CRP $\leq 3.0 \mathrm{mg} / \mathrm{L}$ and normal cognition & 312 & 1 & 1 \\
2: hs-CRP $>3.0 \mathrm{mg} / \mathrm{L}$ and normal cognition & 117 & $1.80(1.24,2.61)$ & $1.70(1.13,2.56)$ \\
3: hs-CRP $\leq 3.0 \mathrm{mg} / \mathrm{L}$ and $\mathrm{Cl}$ & 286 & $2.79(1.82,4.28)$ & $2.39(1.61,3.55)$ \\
4: hs-CRP $>3.0 \mathrm{mg} / \mathrm{L}$ and $\mathrm{Cl}$ & 111 & $4.61(3.16,6.72)$ & $3.56(2.35,5.38)$ \\
P for trend & - & $<0.001$ & $<0.001$ \\
\hline
\end{tabular}

Model 1 adjusted for age and sex; model 2 further adjusted for drinking, smoking, marital status, regular exercise, medication, BMI, central obesity, self-reported history of hypertension, diabetes mellitus, heart disease, stroke and cerebrovascular disease, respiratory disease and cancer. $\mathrm{Cl}=$ cognitive impairment

a $\mathrm{P}$ for interaction $<0.01$

exclusion of early mortality (individuals who died within the first two years of the study) did not attenuate the riskmortality relation appreciably; and (4) with and without adjustment for chronic diseases obtained comparable risk estimates on all-cause mortality (Additional file 1: Table S4).

\section{Discussion}

In our study of 1447 Chinese oldest-old adults we found that hs-CRP and cognition were each independent predictors of all-cause mortality, even after accounting for each other and several traditional mortality risk factors. Significant interaction effects were observed in combined analyses and the combined effects were stronger in male and younger oldest-old (aged 80-89 years) for all-cause mortality prediction.

The results of the individual associations of hs-CRP and cognitive status with all-cause mortality were consistent with previous research $[8,17]$, which showed that both high levels of CRP and poor cognitive function (such as CI) in the oldest-old represent risk factors for mortality, though most of the prior studies have not adequately accounted for each other. For example, in a cohort study [16] of oldest-old aged 90 or older with outcomes being total mortality and incidence of dementia, high levels of CRP (the cutoff value was $5.0 \mathrm{mg} / \mathrm{L}$ ) were associated with greater risk of total mortality [HR: 1.7 (95\% CI, 1.0, 2.9)] after adjustment for APOE4 genotype and other risk factors; however, this study did not consider the impact of cognition on the relationship between CRP exposure and mortality. Another cohort study [31] of 340 centenarians (mean age 101 years) with explanatory variables that included cognition and CRP levels found that higher MMSE scores were related with lower 1-year risk of mortality [HR: 0.978 (95\% CI, 0.946, 0.993)] (P each point $<0.01$ ), but they did not consider the influence of CRP levels on the relationship between cognition and mortality. Other long-term follow-up (more than 7 years) prospective studies [32-34] in community-based aged populations also observed that $\mathrm{CI}$ was associated with increased risk of mortality; similarly, none of them considered the effects of CRP levels on the association.

To the best of our knowledge, this is the first cohort study to examine the combined effect of CRP and cognition on mortality among oldest-old aged 80 years or older in China. One prior study [13] among 6817 German unselected participants aged 65 years or older found significant interaction effects between age [HR CRP > $3.0 \mathrm{mg} / \mathrm{L} \& \geq 75$ years: 3.18 (95\% CI, 2.69, 3.75)], sex [HR CRP $>3.0 \mathrm{mg} / \mathrm{L}$ \& male: 2.25 (95\% CI, 1.92, 2.63)], and arterial hypertension [HR CRP $>3.0 \mathrm{mg} / \mathrm{L} \& \mathrm{SBP} \geq 140$

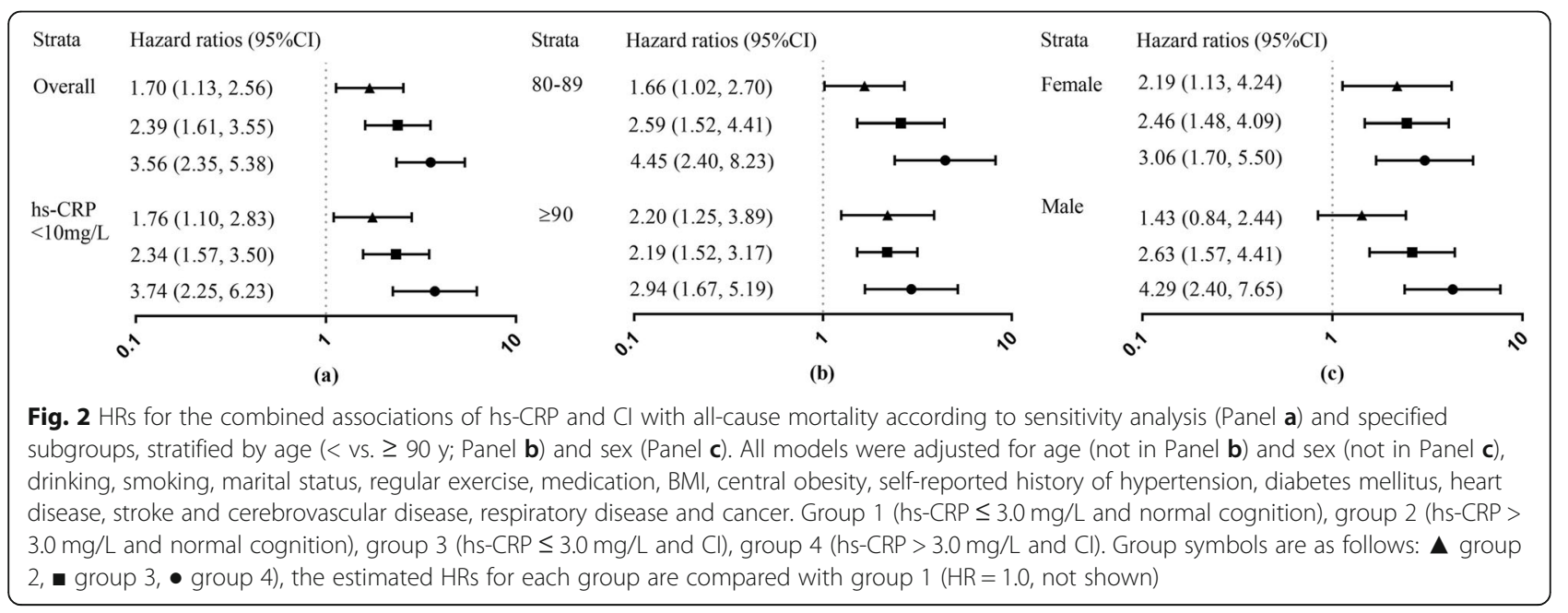


mmHg: $1.30(1.10,1.54)]$ with CRP (the cutoff value was $3.0 \mathrm{mg} / \mathrm{L}$ ) on all-cause mortality. Our study extends the previous work by including a more comprehensive consideration of additional mortality risk factors such as a more accurate assessment of inflammation pathway biomarkers and study of a population of oldest-old of selected without consideration of function.

There are several explanations for the potential additive or combined effect of CRP levels and cognitive limitations on mortality risk in older adults. Firstly, oldest-old individuals with cognitive decline may be more likely to have financial difficulties and therefore less able to manage their health $[35,36]$ and access treatment (the proportion with a better economic status was lower in the CI group in our study, data not shown) when they have a preclinical symptom such as inflammation, thereby increasing their risk of long-term comorbidity [37] and related mortality. Secondly, elevated CRP levels were associated with greater cognitive decline [20,38], which indicates that inflammatory mechanisms may contribute to $\mathrm{CI}$, though it is unclear whether peripheral inflammation is a by-product of neuropathology or whether it directly contributes to cognitive damage [39]. In this case, persons with combined risk indicators of both high hs-CRP and CI, might be expected to have a higher degree of inflammation and thereby a greater risk of mortality than those with elevation of a single components.

In our study, the 4-level joint hs-CRP/cognition variable appeared to be more sensitive in male and younger oldest-old (aged 80-89 years) for all-cause mortality prediction. The smaller estimates among relatively older adults may be partially caused by survival bias [28]. Our study was focused on the Chinese oldest-old; therefore, this association warrants further investigation in other ethnic and age groups.

The nationally representative sample of the oldest-old population in China and the availability of blood samples in a relatively large sample size provided a unique opportunity to estimate the interrelationships among hsCRP levels, cognitive function and all-cause mortality in the oldest-old [24]. The comprehensive information on self-reported history of chronic diseases and physical examinations at baseline made it possible to control the potential confounding bias of these covariates on mortality [28].

The current study nevertheless had several limitations. Firstly, our study had only one measure of inflammation, hs-CRP, that may be subject to the bias of regression dilution; the presence of regression dilution would be to attenuate the effect estimates and therefore could mean that our results underestimate the association of hsCRP and mortality [40]. Furthermore, the results were not changed much by excluding the participants with hsCRP level higher than $10 \mathrm{mg} / \mathrm{L}$; this is supportive evidence that our results are not chance findings. Secondly, we could not ignore the potential overadjustment bias as some of the chronic diseases may be mediatorson the causal pathways from exposures (hs-CRP or cognition) to outcome (mortality)-but not confounders, which would bias the risk estimates to the null. Although the results were nearly identical after these chronic diseases were excluded from the adjusted models, the complex causal pathways in relation to survival with multiple confounders and mediators warranted further investigation. Thirdly, cause-specific death data were not available in our study so we could not compare whether the HRs of the hs-CRP/cognition combined effects were significantly different between vascular and non-vascular mortality [41].

\section{Conclusion}

In conclusion, we found that the oldest-old in China with concurrently elevated hs-CRP and cognition impairment were at the highest risk of all-cause mortality. The combined effect was stronger in male and younger oldest-old for all-cause mortality prediction. Additional research is needed to describe both the specific and combined effects of inflammation and cognition on mortality as well as the biological mechanism underlying these associations.

\section{Supplementary information}

Supplementary information accompanies this paper at https://doi.org/10. 1186/s12979-019-0170-y.

Additional file 1: Table S1. Baseline characteristics of study participants across the 4 groups ( $N=1447)$. Table S2. Baseline characteristics of study participants by follow-up status ( $N=1447)$. Table $\mathbf{S 3}$. Hazard ratios for the individual associations of hs-CRP level and cognitive function with allcause mortality ( $N=1447$ ). Table $\mathbf{S 4}$. Hazard ratios for the combined associations of hs-CRP and cognitive impairment with all-cause mortality, without adjustment for chronic diseases $(N=1447)$.

\section{Abbreviations}

BMl: Body mass index; Cl: Cognitive impairment; CLHLS: Chinese Longitudinal Healthy Longevity Survey; HRs: Hazard ratios; Hs-CRP: High sensitivity Creactive protein; MMSE: Mini-Mental Status Examination; SD: standard deviation; WC: Waist circumference

\section{Acknowledgements}

None.

\section{Authors' contributions}

CC and YCL contributed equally to the concept and data analysis of the manuscript. XMS and YZ designed the survey. YBL helped to conduct the data analysis. ZYL, CM, VBK and XMS contributed to check the accuracy of data analysis and gave efforts on manuscript revision. Other authors helped to implement field investigation and framework construction. All authors read and approved the final manuscript.

\section{Funding}

The Chinese Longitudinal Healthy Longevity Survey, which provided the data analysed in this article, is jointly supported by the National Natural Sciences Foundation of China (71233001, 71490732, 81872707, and 81573247), the US National Institute of Ageing (2P01AG031719), the United 
Nations Fund for Population Activities, and a grant from the Claude D Pepper Older Americans Independence Center (5P30 AG028716 from the National Institute of Ageing to VBK).

\section{Availability of data and materials}

The datasets used and/or analyzed during the current study are available from the corresponding author on reasonable request.

\section{Ethics approval and consent to participate}

The study was approved by the Ethics Committee of Peking University and Duke University. All participants signed written informed consent.

\section{Consent for publication}

All authors have given their consent for the publication of this study.

\section{Competing interests}

The authors declare that they have no competing interests.

\section{Author details}

${ }^{1}$ National Institute of Environmental and Health, Chinese Center for Disease Control and Prevention, Bejing 100021, People's Republic of China. 'Division of Non-communicable Disease and Healthy Ageing Management, Chinese Center for Disease Control and Prevention, Beijing 102206, China. ${ }^{3}$ Department of Pathology, Yale School of Medicine, New Haven, CT 06511, USA. ${ }^{4}$ Division of Epidemiology, School of Public Health, Southern Medical University, Guangzhou 510515, Guangdong, China. ${ }^{5}$ Center for Global Health, School of Public Health, Nanjing Medical University, Nanjing 211166, Jiangsu, China. ${ }^{6}$ Duke Molecular Physiology Institute and Department of Medicine, Duke University School of Medicine, Durham, North Carolina 27711, USA. ${ }^{7}$ Center for the study of Aging and Human Development and the Geriatric Division, School of Medicine, Duke University, Durham, North Carolina 27711, USA. ${ }^{8}$ Center for Healthy Aging and Development Studies, National School of Development, Peking University, Beijing 100871, China.

\section{Received: 25 August 2019 Accepted: 11 November 2019}

\section{Published online: 17 November 2019}

\section{References}

1. Alexander RW. Inflammation and coronary artery disease. Mass Medical Soc. 1994. https://doi.org/10.1056/NEJM199408183310709.

2. Collaboration ERF. C-reactive protein concentration and risk of coronary heart disease, stroke, and mortality: an individual participant meta-analysis. Lancet. 2010;375(9709):132-40. https://doi.org/10.1016/S01406736(09)61717-7.

3. Ridker PM, Rifai N, Rose L, Buring JE, Cook NR. Comparison of C-reactive protein and low-density lipoprotein cholesterol levels in the prediction of first cardiovascular events. N Engl J Med. 2002;347(20):1557-65. https://doi. org/10.1056/NEJMoa021993.

4. Pai JK, Pischon T, Ma J, et al. Inflammatory markers and the risk of coronary heart disease in men and women. N Engl J Med. 2004;351(25):2599-610. https://doi.org/10.1056/NEJMoa040967.

5. Simanek AM, Dowd JB, Pawelec G, Melzer D, Dutta A, Aiello AE. Seropositivity to cytomegalovirus, inflammation, all-cause and cardiovascular disease-related mortality in the United States. PLoS One. 2011;6(2):e16103. https://doi.org/10.1371/journal.pone.0016103.

6. Boekholdt SM, Hack CE, Sandhu MS, et al. C-reactive protein levels and coronary artery disease incidence and mortality in apparently healthy men and women: the EPIC-Norfolk prospective population study 1993-2003. Atherosclerosis. 2006;187(2):415-42. https://doi.org/10.1016/j.atherosclerosis. 2005.09.023.

7. Roberts ET, Haan MN, Dowd JB, Aiello AE. Cytomegalovirus antibody levels, inflammation, and mortality among elderly Latinos over 9 years of followup. Am J Epidemiol. 2010;172(4):363-71. https://doi.org/10.1093/aje/kwq177.

8. Li Y, Zhong $X$, Cheng G, et al. Hs-CRP and all-cause, cardiovascular, and cancer mortality risk: a meta-analysis. Atherosclerosis. 2017;259:75-82. https://doi.org/10.1016/j.atherosclerosis.2017.02.003.

9. Myers GL, Christenson RH, Cushman M, et al. National Academy of Clinical Biochemistry Laboratory medicine practice guidelines: emerging biomarkers for primary prevention of cardiovascular disease. Clin Chem. 2009:55(2):37884. https://doi.org/10.1373/clinchem.2008.115899.
10. Pearson TA, Mensah GA, Alexander RW, et al. Markers of inflammation and cardiovascular disease: application to clinical and public health practice: a statement for healthcare professionals from the Centers for Disease Control and Prevention and the American Heart Association. Circulation. 2003; 107(3):499-511. https://doi.org/10.1161/01.CIR.0000052939.59093.45.

11. Koenig W, Khuseyinova N, Baumert J, Meisinger C. Prospective study of high-sensitivity C-reactive protein as a determinant of mortality: results from the MONICA/KORA Augsburg cohort study, 1984-1998. Clin Chem. 2008; 54(2):335-42. https://doi.org/10.1373/clinchem.2007.100271.

12. Kim K-I, Oh SW, Ahn S, et al. CRP level and HDL cholesterol concentration jointly predict mortality in a Korean population. Am J Med. 2012;125(8):787795. e4. https://doi.org/10.1016/j.amjmed.2012.02.013.

13. Rudolf $\mathrm{H}$, Wall $\mathrm{N}$, Klaassen-Mielke $\mathrm{R}$, et al. Interactions between $\mathrm{C}$-reactive protein and traditional risk factors in predicting mortality of older adults. Vasa. 2017:46(2):127-33. https://doi.org/10.1024/0301-1526/a000599.

14. Störk S, Feelders RA, van den Beld AW, et al. Prediction of mortality risk in the elderly. Am J Med. 2006;119(6):519-25. https://doi.org/10.1016/j.amjmed. 2005.10.062.

15. Strandberg TE, Tilvis RS. C-reactive protein, cardiovascular risk factors, and mortality in a prospective study in the elderly. Arterioscler Thromb Vasc Biol. 2000;20(4):1057-60. https://doi.org/10.1161/01.ATV.20.4.1057.

16. Kravitz BA, Corrada MM, Kawas CH. High levels of serum C-reactive protein are associated with greater risk of all-cause mortality, but not dementia, in the oldest-old: results from the 90+ study. J Am Geriatr Soc. 2009;57(4):6416. https://doi.org/10.1111/j.1532-5415.2009.02169.x.

17. Dewey ME, Saz P. Dementia, cognitive impairment and mortality in persons aged 65 and over living in the community: a systematic review of the literature. Int J Geriatr Psychiatry. 2001;16(8):751-61. https://doi.org/10.1002/ gps.397.abs.

18. Duong T, Nikolaeva M, and Acton PJ. C-reactive protein-like immunoreactivity in the neurofibrillary tangles of Alzheimer's disease. Brain Res, 1997, 749(1): 152-156. https://doi.org/10.1016/S0006-8993(96)01359-5.

19. Gorelick PB. Role of inflammation in cognitive impairment: results of observational epidemiological studies and clinical trials. Ann N Y Acad Sci. 2010;1207(1):155-62. https://doi.org/10.1111/j.1749-6632.2010.05726.x.

20. Metti AL, Yaffe $K$, Boudreau RM, et al. Trajectories of inflammatory markers and cognitive decline over 10 years. Neurobiol Aging. 2014;35(12):2785-90. https://doi.org/10.1016/j.neurobiolaging.2014.05.030.

21. Singh-Manoux A, Dugravot A, Brunner $E$, et al. Interleukin-6 and C-reactive protein as predictors of cognitive decline in late midlife. Neurology. 2014; 83(6):486-93. https://doi.org/10.1212/WNL.0000000000000665.

22. Mao C, Yuan JQ, LV YB, et al. Associations between superoxide dismutase, malondialdehyde and all-cause mortality in older adults: a communitybased cohort study. BMC Geriatr. 2019;19(1):104. https://doi.org/10.1186/ s12877-019-1109-z.

23. Zeng Y, Poston DLJ, Vlosky DA, Gu D. Healthy longevity in China: demographic, socioeconomic, and psychological dimensions. Dordrecht: Springer Netherlands; 2008.

24. Yi Z, Shi XM, Fitzgerald SM, et al. High sensitivity C-reactive protein associated with different health predictors in middle-aged and oldest old Chinese. Biomed Environ Sci. 2012;25(3):257-66.

25. Crum RM, Anthony JC, Bassett SS, Folstein MF. Population-based norms for the mini-mental state examination by age and educational level. Jama. 1993;269(18):2386-91. https://doi.org/10.1001/jama.269.18.2386.

26. Cui GH, Yao YH, Xu RF, et al. Cognitive impairment using education-based cutoff points for CMMSE scores in elderly Chinese people of agricultural and rural Shanghai China. Acta Neurol Scand. 2011;124(6):361-7. https://doi.org/ 10.1111/j.1600-0404.2010.01484.X.

27. LV Y-B, Liu S, Yin Z-X, et al. Associations of body mass index and waist circumference with 3-year all-cause mortality among the oldest old: evidence from a Chinese community-based prospective cohort study. J Am Med Dir Assoc. 2018. https://doi.org/10.1016/j.jamda.2018.03.015.

28. Liu Z, Han L, Wang X, Feng Q, Gill TM. Disability prior to death among the oldest-old in China. J Gerontology A. 2018:gly010. https://doi.org/10.1093/ gerona/gly010.

29. Kang $L$, Chen W, Petrick NA, Gallas BD. Comparing two correlated C indices with right-censored survival outcome: a one-shot nonparametric approach. Stat Med. 2015:34(4):685-703. https://doi.org/10.1002/sim.6370.

30. Landry A, Docherty P, Ouellette S, Cartier LJ. Causes and outcomes of markedly elevated C-reactive protein levels. Can Fam Physician. 2017:63(6): e316-23. 
31. Mossakowska M, Broczek K, Wieczorowska-Tobis K, et al. Cognitive performance and functional status are the major factors predicting survival of centenarians in Poland. J Gerontol A Biol Sci Med Sci. 2014;69(10):126975. https://doi.org/10.1093/gerona/glu003.

32. de Bruijn RF, Akoudad S, Cremers LG, et al. Determinants, MRI correlates, and prognosis of mild cognitive impairment: the Rotterdam study. J Alzheimers Dis. 2014;42(s3):S239-49. https://doi.org/10.3233/JAD-132558.

33. Sachs GA, Carter R, Holtz LR, et al. Cognitive impairment: an independent predictor of excess mortality: a cohort study. Ann Intern Med. 2011;155(5): 300-8. https://doi.org/10.7326/0003-4819-155-5-201109060-00007.

34. Wilson RS, Aggarwal NT, Barnes LL, Bienias JL, de Leon CFM, Evans DA. Biracial population study of mortality in mild cognitive impairment and Alzheimer disease. Arch Neurol. 2009;66(6):767-72. https://doi.org/10.1001/ archneurol.2009.80.

35. Basta NE, Matthews FE, Chatfield MD, Brayne C. And MRC-CFAS

Community-level socio-economic status and cognitive and functional impairment in the older population. Eur J Pub Health. 2007;18(1):48-54. https://doi.org/10.1093/eurpub/ckm076.

36. Choi H, Schoeni RF, Martin LG, Langa KM. Trends in the prevalence and disparity in cognitive limitations of Americans 55-69 years old. J Gerontol B Psychol Sci Soc Sci. 2018;73(suppl_1):S29-37. https://doi.org/10.1093/ geronb/gbx155.

37. Stepanova M, Rodriguez E, Birerdinc A, Baranova A. Age-independent rise of inflammatory scores may contribute to accelerated aging in multimorbidity. Oncotarget. 2015;6(3):1414. https://doi.org/10.18632/oncotarget. 2725.

38. Yaffe $K$, Lindquist $K$, Penninx $B$, et al. Inflammatory markers and cognition in well-functioning African-American and white elders. Neurology. 2003;61(1): 76-80. https://doi.org/10.1212/01.WNL.0000073620.42047.D7.

39. Jack CR Jr, Knopman DS, Jagust WJ, et al. Hypothetical model of dynamic biomarkers of the Alzheimer's pathological cascade. Lancet Neurol. 2010; 9(1):119-28. https://doi.org/10.1016/S1474-4422(09)70299-6.

40. Emberson JR, Whincup PH, Morris RW, Walker M, Lowe GD, Rumley A. Extent of regression dilution for established and novel coronary risk factors: results from the British regional heart study. Eur J Cardiovasc Prev Rehabil. 2004;11(2):125-34. https://doi.org/10.1097/01.hjr.00001 14967.39211.e5.

41. Willems JM, Trompet S, Blauw GJ, Westendorp RG, de Craen AJ. White blood cell count and C-reactive protein are independent predictors of mortality in the oldest old. J Gerontol A Biol Sci Med Sci. 2010;65(7):764-8. https://doi.org/10.1093/gerona/glq004.

\section{Publisher's Note}

Springer Nature remains neutral with regard to jurisdictional claims in published maps and institutional affiliations.

Ready to submit your research? Choose BMC and benefit from:

- fast, convenient online submission

- thorough peer review by experienced researchers in your field

- rapid publication on acceptance

- support for research data, including large and complex data types

- gold Open Access which fosters wider collaboration and increased citations

- maximum visibility for your research: over $100 \mathrm{M}$ website views per year

At $\mathrm{BMC}$, research is always in progress.

Learn more biomedcentral.com/submissions 